\title{
An unusual presentation of a vaginal leiomyoma in a postmenopausal hysterectomised woman: a case report Smitha V Nidhanee ${ }^{1 *}$, Sachchidananda Maiti ${ }^{1}$, Dillshad Shareef ${ }^{2}$ and Nigel Holland ${ }^{1}$
}

Address: ${ }^{1}$ Department of Obstetrics and Gynaecology, ${ }^{2}$ Department of Histopathology, Warrington and Halton Hospitals, NHS Foundation Trust, WA5 1QG, United Kingdom

Email: SN* - drsmitha27@yahoo.co.in; SM -d_maiti@yahoo.co.uk; DS - Dillshad.Shareef@nch.nhs.uk; NH - nigel.holland@nch.nhs.uk

* Corresponding author

Published: 10 March 2009

Cases Journal 2009, 2:646I doi: 10.1 I86/I757-|626-2-646I

This article is available from: http://casesjournal.com/casesjournal/article/view/2/3/646I

(c) 2009 Nidhanee et al; licensee Cases Network Ltd.

This is an Open Access article distributed under the terms of the Creative Commons Attribution License (http://creativecommons.org/licenses/by/3.0), which permits unrestricted use, distribution, and reproduction in any medium, provided the original work is properly cited.
Received: 26 December 2008

Accepted: 17 February 2009

\begin{abstract}
Leiomyomas are benign tumours commonly occurring in the uterine wall. They are rarely seen in the vaginal wall leading to pressure symptoms on urinary tract. Indentation of leiomyoma from anterior vaginal wall into the bladder is rare and hence we report one such case. A 55 year old Caucasian woman presented to urology clinic with recurrent Urinary tract infection and pressure symptoms. After the diagnosis of a vaginal mass, she was referred to Gynaecology clinic. During the excision of the vaginal mass its indentation into the bladder was noted. Histology report confirmed the diagnosis of benign leiomyoma.
\end{abstract}

\section{Introduction}

The vagina is a rare site for leiomyoma, and they are usually located in the anterior wall and rarely from the lateral wall [1]. They usually present as a mass in the vagina or as pressure symptoms on the urinary tract $[2,3]$. We report a case of leiomyoma arising from the anterior wall of vagina indenting laterally into the bladder wall, which lead to difficulties in its excision and subsequent bladder injury which was repaired eventually.

\section{Case presentation}

A 55-year-old Caucasian woman presented to the urology clinic with complaints of sensation of pressure in suprapubic area with symptoms suggesting of possible cystitis for last twelve months. She had been treated for recurrent urinary tract infections in the past. She denied any dyspareunia and bowel dysfunction. She had two normal vaginal deliveries. She had undergone total abdominal hysterectomy 10 years ago and was on hormone replacement therapy for last five years.

Trans-abdominal and trans-vaginal ultrasound scan revealed a $3 \mathrm{~cm}$ mixed echo solid mass indenting the urinary bladder in the distal anterior vaginal wall (Figure 1 $\& 2)$. At this stage she was referred to the gynaecology team.

Gynaecological examination revealed that the vault was well supported with a small cystocele and rectocele and a $3-4 \mathrm{~cm}$ mobile cystic mass was palpable on the anterior vaginal wall about $1 \mathrm{~cm}$ from the vault. Subsequently, 


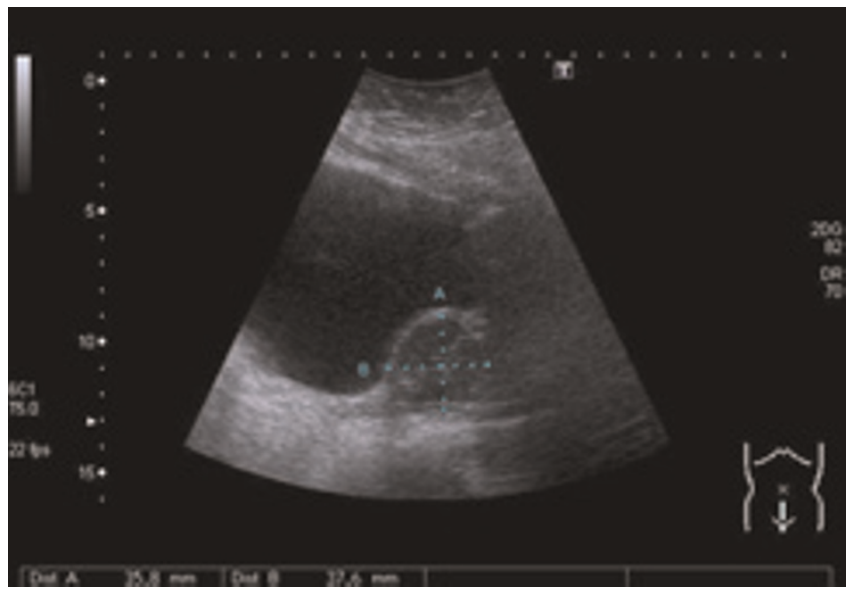

Figure I.

Trans-abdominal scan.

during examination under anaesthesia with a urologist in attendance, $3-4 \mathrm{~cm}$ solid mobile anterior vaginal mass was noted extending along the lateral vaginal wall. In an attempt to completely enucleate the mass, a small perforation was accidentally made in the bladder wall. The tumour was removed completely in piecemeal and sent for histopathology. The bladder was repaired in 2 layers by the urologist.

She was discharged home on the third post operative day with catheter in situ and 10 days of antibiotics. Catheter was removed on the $10^{\text {th }}$ day following normal cystogram. Histology report showed smooth muscle tumour consisting of uniform smooth muscle cells without pleomorphism/mitotic activity thereby confirming benign vaginal leiomyoma (Figure 3, 4 \& 5)

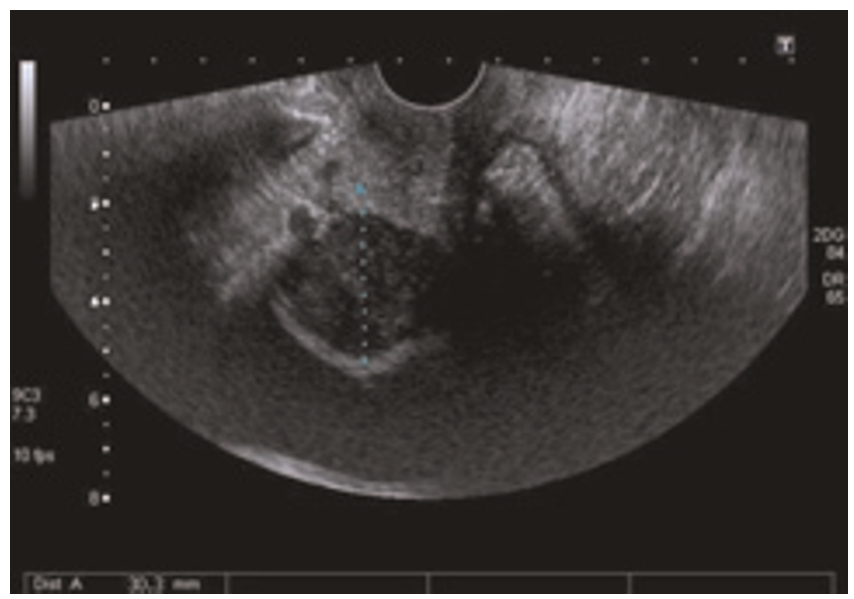

Figure 2.

Trans-vaginal scan.

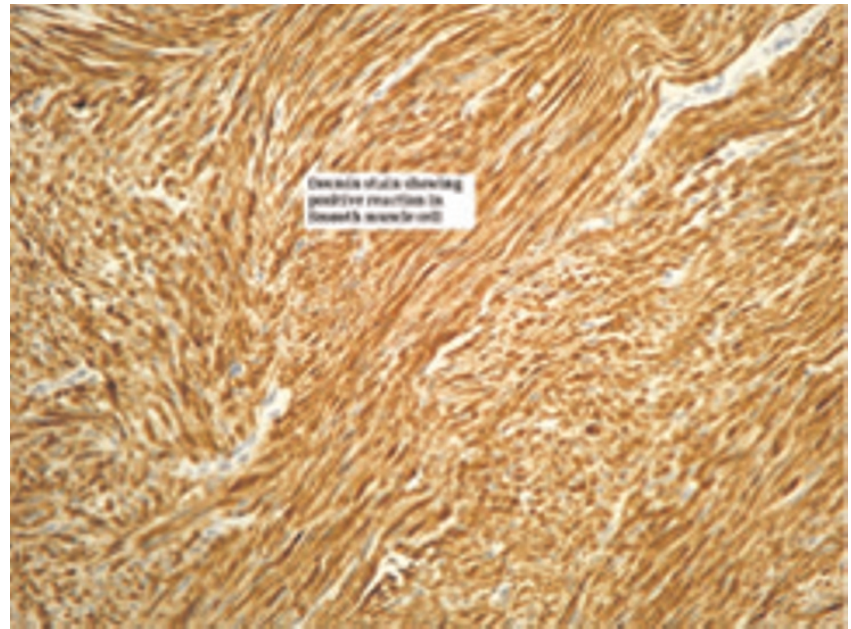

Figure 3.

Desmin stain showing positive reaction in tumour cells.

\section{Discussion}

Over 300 cases of vaginal leiomyomas have been reported in the literature. They have varied clinical presentation, the most common being vaginal mass $[4,5]$.

Vaginal myomas have been reported in patients from puberty to 71 years of age [6]. Average age of diagnosis tends to be in late 30 s or early 40 s. Vaginal myomas can be asymptomatic. When symptoms present, they commonly are related to the urinary tract and include voiding difficulties, dysuria and urinary frequency. The most common gynaecological complaint is dyspareunia. However, many patients only describe a bulging mass [6].

These lesions tend to be single and less than $5 \mathrm{~cm}$ in diameter which are usually localised and vary from solid

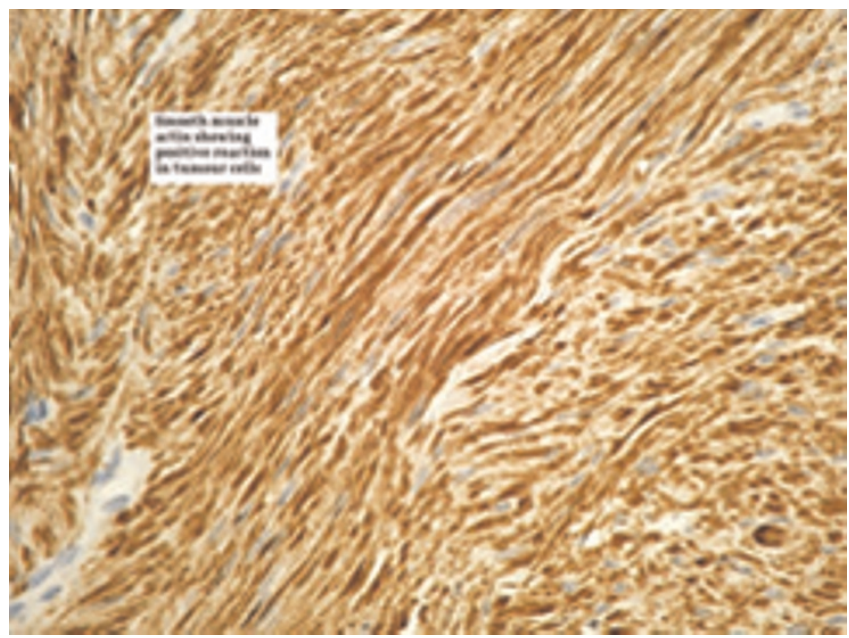

Figure 4.

Smooth muscle cells showing positive reaction to actin. 


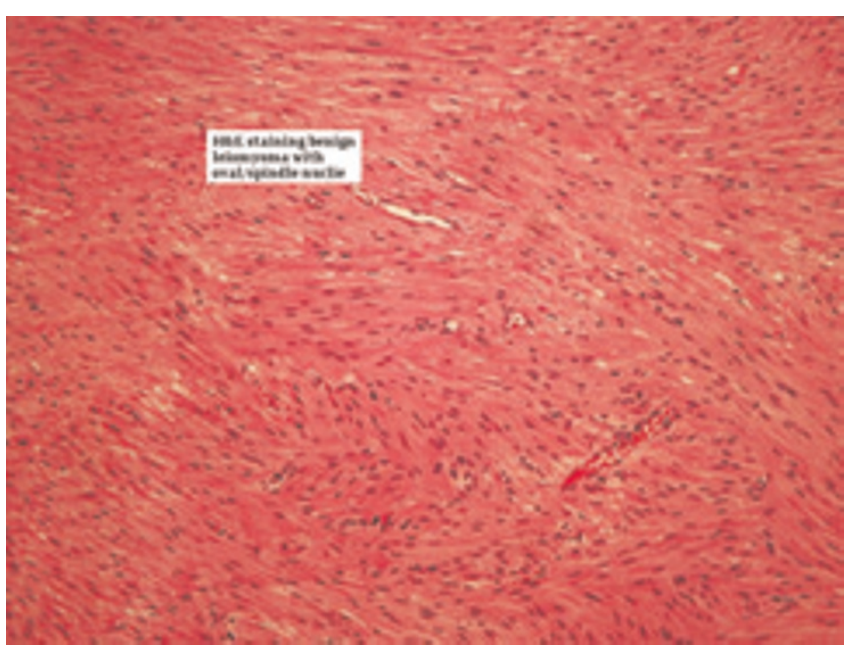

Figure 5.

Hematoxylin \& Eosin stain showing benign leiomyoma with uniform oval/spindle nuclei.

to cystic in consistency. They are usually firm and can undergo degenerative changes and feel soft [7]. The majority are found in the anterior wall of the vagina and only 10 to $20 \%$ are found in the lateral wall.

They may be confused with a variety of benign vaginal tumours. A preoperative diagnosis is seldom made.

Though surgery through vaginal route is the treatment of choice, recurrence is of concern. Some authors have specifically recommended removal of the tumour enbloc to avoid any possible recurrence [7].

Indentation of Leiomyoma from the vaginal wall into the urinary bladder has not been reported in the literature. The purpose of presenting this case report is to emphasize that benign leiomyomas can present with just urinary symptoms. Though benign they can indent the bladder wall, which can render the surgical excision difficult with out damaging the bladder wall. We strongly recommend high index of suspicion of bladder injuries in such cases. We also recommend involving urologist during the surgery if required for the repair of the bladder.

\section{Conclusion}

Benign vaginal leiomyomas indenting the bladder wall is challenging to excise. We conclude that patient should be consented for the possibility of bladder injury and its complications in all such cases.

\section{Consent}

Written informed consent was obtained from the patient for publication of this case report and accompanying images. A copy of the written consent is available for review by the Editor-in-Chief of this journal.

\section{Competing interests}

The authors declare that they do not have any competing interest.

\section{Author's contribution}

SN wrote the draft of the manuscript, performed the literature search and was involved in the care of the patient. SM supervised and finalised the manuscript. NH and DS contributed to her care and helped with the manuscript.

\section{Acknowledgement}

The authors acknowledge the patient for consenting to reveal the case details and photographs for publication.

\section{References}

I. Kaufman RH, Gardner HL: Benign mesodermal tumors. Clin Obste gynaecol 1965, 8:978.

2. Sangwan K, Khosla AH, Hazra PC: Leiomyoma of the vagina. Aust NZ Obstet Gynaecol 1996, 36:494-495.

3. Njeh MB, Barkia A, Jemni M, Zermani R, Ben Milad K, Ayed M: Vagianl leiomyoma. The female prostate. Acta Urol Belg 1993, 6 I (3):3I-32.

4. Ruggieri AM, Brody JM, Curhan RP: Vaginal leiomyoma. A case report with imaging findings. J Reprod Med I996, 4 I ( I I):875-877.

5. Neil CP, Tiltman AJ: Leiomyoma Of vagina. S Afr Med J I978, 54:816-817.

6. Pulfus E and Newcomer J: Vaginal wall mass: Guest editorial. Obstetrical and gynaecological survey 1999, 54:149-I50.

7. Gowri R, Soundararaghavan S, Oumachigui A, Sistla SC and lyengar KR: Leiomyoma of the vagina: An unusual presentation. J Obstet Gynaecol Res 2003, 29:395-398.

\section{Do you have a case to share?}

\section{Submit your case report today}

- Rapid peer review

- Fast publication

- PubMed indexing

- Inclusion in Cases Database

\section{Any patient, any case, can teach us something}

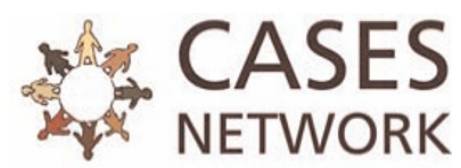

www.casesnetwork.com 